\title{
Altered Expression of ORAI and STIM Isoforms in Activated Human Cardiac Fibroblasts
}

\author{
Róbert ČENDULA ${ }^{1}$, Nikola CHOMANIČOVÁ ${ }^{1}$, Adriana ADAMIČKOVÁ ${ }^{2}$, Andrea \\ GAŽOVÁ ${ }^{3}$, Ján KYSELOVIČํ, Marek MÁŤUS̆ ${ }^{1}$
}

${ }^{1}$ Department of Pharmacology and Toxicology, Faculty of Pharmacy, Comenius University in Bratislava, Bratislava, Slovak Republic, ${ }^{2} 5^{\text {th }}$ Department of Internal Medicine, University Hospital Bratislava - Ružinov, Bratislava, Slovak Republic, ${ }^{3}$ Institute of Pharmacology and Clinical Pharmacology, Faculty of Medicine, Comenius University in Bratislava, Bratislava, Slovak Republic

Received June 14, 2021

Accepted July 27, 2021

\begin{abstract}
Summary
Cardiac fibrotization is a well-known process characteristic of many cardiac pathological conditions. The key element is excessive activation of cardiac fibroblasts, their transdifferentiation into myofibroblasts, increased production, and accumulation of extracellular matrix proteins, resulting in cardiac stiffness. The exact cellular mechanisms and molecular components involved in the process are not fully elucidated, but the SOCE mechanism could play an important role. Its key molecules are the molecular sensor of calcium in ER/SR - STIM and the highly selective calcium channels Orai located in the plasma membrane. This study aims to evaluate selected SOCEassociated genes in the activation of HCF cell culture by several known substances (phenylephrine, isoprenaline) that represent cardiovascular overload. After cell cultivation, cell medium was collected to measure the soluble collagen content. From the harvested cells, qRT-PCR was performed to determine the mRNA levels of the corresponding genes. The activation of cells was based on changes in the relative expression of collagen genes as well as the collagen content in the medium of the cell culture. We detected an increase in the expression of the Orai2 isoform, a change in the Orai1/Orai3 ratio and also an increase in the expression of the STIM2 isoform. These results suggest an increased activation of the SOCE mechanism under stress conditions of fibroblasts, which supports the hypothesis of fibroblast activation in pathological processes by altering calcium homeostasis through the SOCE mechanism.
\end{abstract}

\section{Key words}

Human cardiac fibroblast (HCF) • SOCE (Store-operated calcium entry) • Orai • STIM

\section{Corresponding author}

Marek Mát'uš, Department of Pharmacology and Toxicology, Faculty of Pharmacy, Comenius University in Bratislava, Odbojarov 10, 83232 Bratislava, Slovak republic. Email: matus@fpharm.uniba.sk

\section{Introduction}

Although most of the heart mass consists of cardiomyocytes, cardiac fibroblasts are one of the most numerous cells in the heart. These cells produce growth factors and other signaling molecules that directly regulate cardiomyocyte function, form the basal structure of the heart, and provide stability and elasticity of the heart by creating a network of support for cardiomyocytes consisting of ECM proteins such as collagens and $\alpha$-SMA (Chen et al. 2021). Despite the irreplaceable role of cardiac fibroblasts in heart physiology, disease-activated fibroblasts, traditionally referred to as myofibroblasts, are characterized by excessive activation and specialization in the secretion of ECM proteins, which over time leads to pathological myocardial stiffness and progressively worsening cardiac function caused by excessive accumulation of collagens and other ECM proteins throughout the heart (Tallquist et al. 2017). Despite the primary reparative function of fibroblasts in the heart, the influence of many key modulators such as different growth factors (TNF- $\alpha$, PDGF, TGF- $\beta$ ), cytokines (IL-1, IL-10, IL-11), reninangiotensin system (RAS) and microRNA causes excessive and prolonged activation that manifests in the 
onset and progression of cardiac fibrosis as a maladaptive process (Ranjan et al. 2019). Current therapeutic possibilities in the prevention and treatment of excessive cardiac fibrotization, which is an essential factor in the pathophysiology of many heart diseases, are limited. Identifying novel molecular components and signaling pathways associated with cardiac fibrosis could serve a dual purpose, as a potentially innovative therapy and also as new diagnostic markers. This even more emphasizes the importance of studying the cellular pathways and molecular components involved in this process (Ceccato et al. 2020). Although it is clear that calcium signaling plays a crucial role in the pathological activation of fibroblasts, due to the large and diverse number of receptors, transporters, and ion channels that affect intracellular $\mathrm{Ca}^{2+}$ kinetics, the key elements of fibroblast transdifferentiation to myofibroblasts have not been fully elucidated (Feng et al. 2019). Store-operated calcium entry (SOCE) is a specific calcium handling mechanism present in virtually all cell types, which has been known for a relatively long period of time. The exact molecular mechanism behind this cellular event was described in 2006, when two main components of the SOCE were described: STIM and Orai were discovered (Putney 2011, Rosenberg et al. 2021). Three genes that encode Orai proteins (Orai1-3) (Ruhle et al. 2013) and two encoding STIM proteins (STIM1-2) are currently known (Wen et al. 2016). STIM is a single-span protein located in the membrane of the (sarco) endoplasmatic reticulum (ER/SR) and acts as a molecular calcium sensor. Depletion of $\mathrm{Ca}^{2+}$ stores induces a conformational change (Muik et al. 2011), which allows STIM after its oligomerization (Covington et al. 2010) to interact with Orai. Orai proteins form in the plasma membrane tetrahexameric channels highly selective for calcium cations (Saul et al. 2014). These channels are opened after interaction with active STIM proteins, which allows the inflow of $\mathrm{Ca}^{2+}$ from the extracellular environment. There are many other critical proteins known to be involved in SOCE such as TRPC channels (Serafini et al. 2020), however, for functional SOCE only Orai and STIM proteins are essential (Lewis 2011). Furthermore, the participation of different Orai isoforms in the formation of heteromeric channels can lead to differences in SOCE properties (Putney et al. 2017). Furthermore, in the posttranscriptional processes of the STIM isoforms, several variants of STIM are formed (STIM1 and 1L, STIM2.1, 2.2, and 2.3) of which the most striking is STIM2.1 for its assumed inhibitory effect on the SOCE mechanism (Rana et al. 2015, Rosado et al. 2016). In the aftermath of these findings, over the last two decades, many studies have implied this voltage-independent $\mathrm{Ca}^{2+}$ entry pathway into cardiac physiology and pathophysiology (Rosenberg et al. 2021). Most of these studies, including ours (Čendula et al. 2019), focused on cardiomyocytes, and many interesting changes were observed in fact (Bootman et al. 2017, Rosenberg et al. 2019). However, SOCE is a predominant mechanism in nonexcitable cells (Hammad et al. 2021), which indicates a critical involvement of this mechanism in cardiac fibroblast activation processes.

\section{Methods}

\section{Cell culture}

In this study, a standard culture of human cardiac fibroblasts (HCF) (SKU: 306-05F, Sigma Aldrich, Germany), purchased as a first passage, stored in cryopreserved medium at $-80^{\circ} \mathrm{C}$, was used. Cell cultures were cultured according to a standard protocol in a humidified incubator of $37{ }^{\circ} \mathrm{C}, 5 \% \mathrm{CO}_{2}$ in $15 \mathrm{ml}$ for a T-75 flask and $5 \mathrm{ml}$ for a $60 \mathrm{~mm}$ cell culture plate in low glucose DMEM (Dulbecco's modified Eagle medium, Sigma Aldrich, Germany) enriched with fetal bovine serum (FBS) at a volume concentration of $10 \%$ with added antibiotics penicillin $(100 \mathrm{IU} / \mathrm{ml})$ and streptomycin $(100 \mu \mathrm{g} / \mathrm{ml})$ at $5 \%$ volume concentration. The medium was changed every third day to reach $80 \%$ confluence. Cell passage was performed by applying a $0.25 \%$ trypsin solution containing EDTA (Sigma Aldrich, Germany) in cell culture for 5-7 minutes. After dilution in cell medium, centrifugation $\left(10\right.$ minutes, $4{ }^{\circ} \mathrm{C}$, $250 \mathrm{G}$ ) and resuspendation of the cell pellet in culture medium in flasks for the next passage. in a cell culture dish for exposure to specific substances. For the experiment, the required $5^{\text {th }}$ passage was transferred to a cell culture plate in an amount of $\sim 0.5 \times 10^{6}$ cells. Cells in plates were exposed for 24 and 48 hours to phenylephrine (PE, Sigma-Aldrich, at final concentrations of $0.1 \mu \mathrm{M}, 1 \mu \mathrm{M}$ and $10 \mu \mathrm{M}$ final concentration in medium) and isoprenaline (ISO, Sigma-Aldrich, at concentrations of $0.1 \mu \mathrm{M}, 1 \mu \mathrm{M}$ and $10 \mu \mathrm{M}$ concentration) without and with specific antagonists prazosin (PZS, Sigma-Aldrich, at concentration of $10 \mu \mathrm{M}$ concentration) and propranolol (PP, Sigma-Aldrich, at concentration $10 \mu \mathrm{M}$ concentration), respectively. The M-795 inverted microscope (OPTIKA S.R.L., Italy) was used to routinely make microscopic observations of the cells. 


\section{Collagen measurement}

Cell culture medium was collected after exposure to analyze the soluble collagen content. The SircolTM Soluble Collagen Assay (Biocolor Ltd., UK) was used in this study, where Sirius Red dye is used to selectively bind and precipitate the soluble collagen. Subsequent elution with acid-salt wash and subsequent dissolution in alkali sodium hydroxide-methanol and read-out at $555 \mathrm{~nm}$ was performed on microtiter plates.

\section{Flow cytometry}

Cell cultures were analyzed by flow cytometry (MACS Quant. Analyzer, Miltenyi Biotec, Germany) Samples were centrifuged and subsequently diluted in cell medium to reach a concentration of $10^{6}$ cells $/ \mathrm{ml}$. To analyze cell viability, propidium iodide (PI, Miltenyi Biotec, Germany) was added to the cell solution. It is capable of binding to nucleic acids of cells with disrupted membrane, representing dead cells. To analyze the phenotype of $\mathrm{HCF}$, an expression combination of positive (CD90, CD105, CD73) and negative surface markers (CD14, CD20, CD34, CD45) was used. Gating strategies according to the manufacturer's instructions were used.

\section{$R N A$ isolation and $q R T-P C R$}

Total RNA was isolated using Tri-Reagent ${ }^{\circledR}$ (Sigma-Aldrich, USA) according to the protocol recommended by the manufacturer. The quality and quantity of isolated RNA was measured by spectrophotometric analysis (NanoDropND-1000, Thermo Scientific, USA). Reverse transcription was performed using HighCapacity cDNA KIT with RNAse inhibitor (Applied Biosystems, USA). SYBR Green detection (SYBR Select Master Mix, Life Technologies, USA) was used to perform quantitative RT-PCR on QuantStudio $^{\text {TM }} 3$ Real-Time PCR System (Applied Biosystems $^{\mathrm{TM}}$, USA) according to manufacturer's instructions. Primers (Sigma-Aldrich, USA) were designed to amplify human Orai1, Orai2, Orai3, STIM1, all variants of STIM2 and variant STIM2.1 only. All primers were verified to produce a single PCR product with the correct molecular weight, and the absence of signal was verified when reverse transcription was omitted. The $\Delta \Delta \mathrm{Ct}$ method was used to determine the relative expression level of the target genes. The $\mathrm{Ct}$ values were normalized to the expressions of endogenous reference genes (HPRT1, hypoxanthine phosphoribosyltransferase 1, B2M, beta-2-microglobulin). The primer sequences used are listed in Table 1.

The PCR efficacy and quantification cycle values for computational and statistical analysis for each sample were determined with the LinRegPCR software (version 2017.1). The Shapiro-Wilk test was used as a normality test. To compare two groups with normally distributed data, Student's T-test was used. Two-way ANOVA was used to assess the differences among multiple groups. Tukey's range test was performed for normally distributed data and the Kruskal-Wallis $H$ test for non-normally distributed data. All data were handled by MS Excel (MicroSoft Office, version 2019), SigmaPlot 12.0 (Systat Software Inc.) and GraphPad Prism (GraphPad Software Inc., version 6). All data are presented as average \pm standard error.

Table 1: Primer sequences used for the qRT-PCR analysis of selected gene expressions.

\begin{tabular}{|c|c|c|}
\hline Gene & Forward primer & Reverse primer \\
\hline$B 2 M$ & TCCGTGGCCTTAGCTGTGCTT & TCCATTCTCTGCTGGATGACGTGAG \\
\hline HPRT1 & AGCCCTGGCGTCGTGATTAGTGA & GGTCACAATGTGATGGCCTCCCA \\
\hline CollA1 & AAGTCATAGGAGTCGAGGGAC & AGGACATCTGGGAAGCAAAGT \\
\hline Col3A1 & AGGGTATCAAGGGTGAAAGTGG & CCTGGCTGACCATCTGATCC \\
\hline hACTA2 & GCCTATCCCCGGGACTAAGACG & GCCGGCCTTACAGAGCCCAGA \\
\hline OraiI1 & CGCCAAGCTTAAAGCCTCCA & CTGATCATGAGCGCAAACAGG \\
\hline Orai2 & CAGCTCCGGGAAGGAACGTC & TAGGCACGTTAAGCTCAGCACT \\
\hline Orai3 & CCACGTACCGGGAGTTCG & GTACTCGTGGTCACTCTCCAG \\
\hline STIM1 & GACTGACGACGTGGATGACA & TACCCGGCTTGTCAAGAAGT \\
\hline STIM2 & TGTCACTGAGTCCACCATGC & тCTCTGTGCAGATGGCTGTG \\
\hline STIM2.1 & AGGTTCGCATGGCTCTGAAA & TGAATCAGATATGAAGCAGCAACC \\
\hline
\end{tabular}



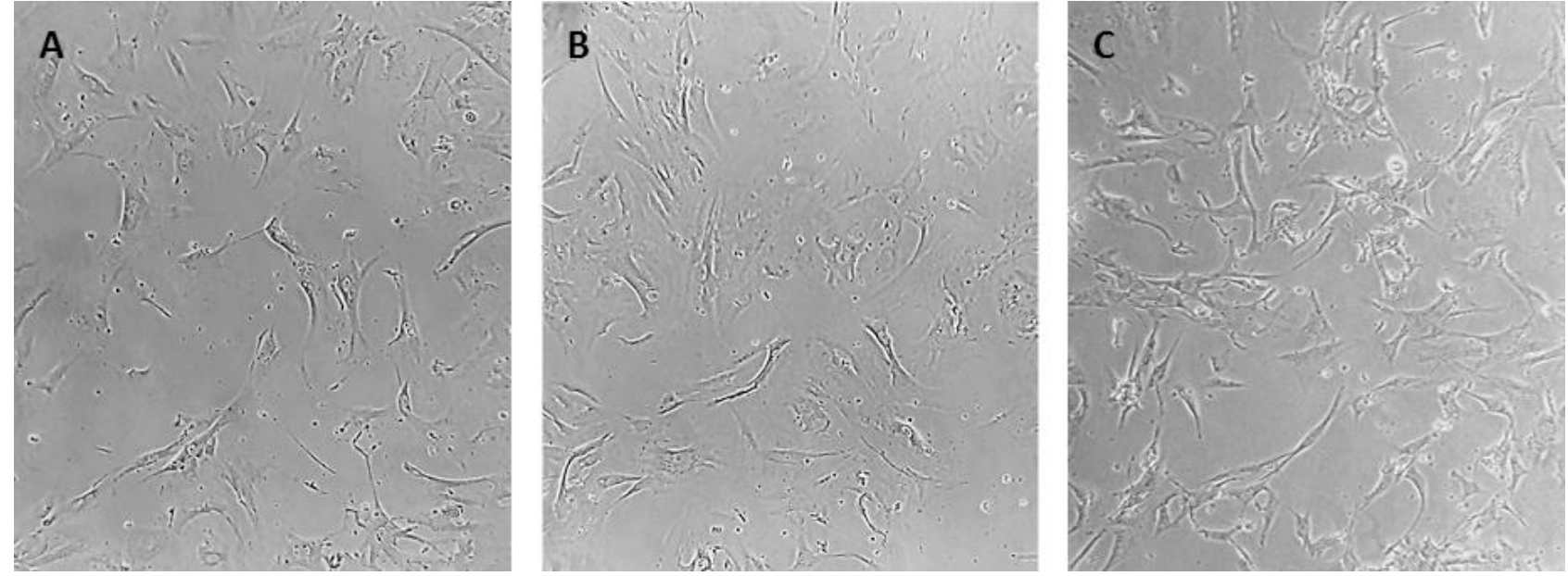

Fig. 1. Microscopic view (20x magnification) of HCF cell culture after 48 hours of cultivation in medium A) control sample (CTR); B) containing $10 \mu \mathrm{M}$ isoprenaline; C) containing $10 \mu \mathrm{M}$ isoprenaline $+10 \mu \mathrm{M}$ propranolol.

Cell count

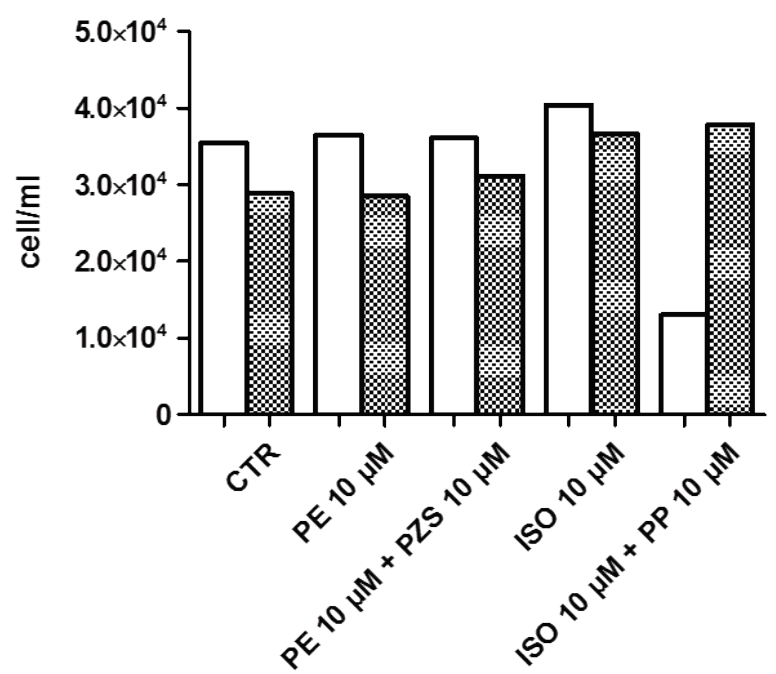

Viability

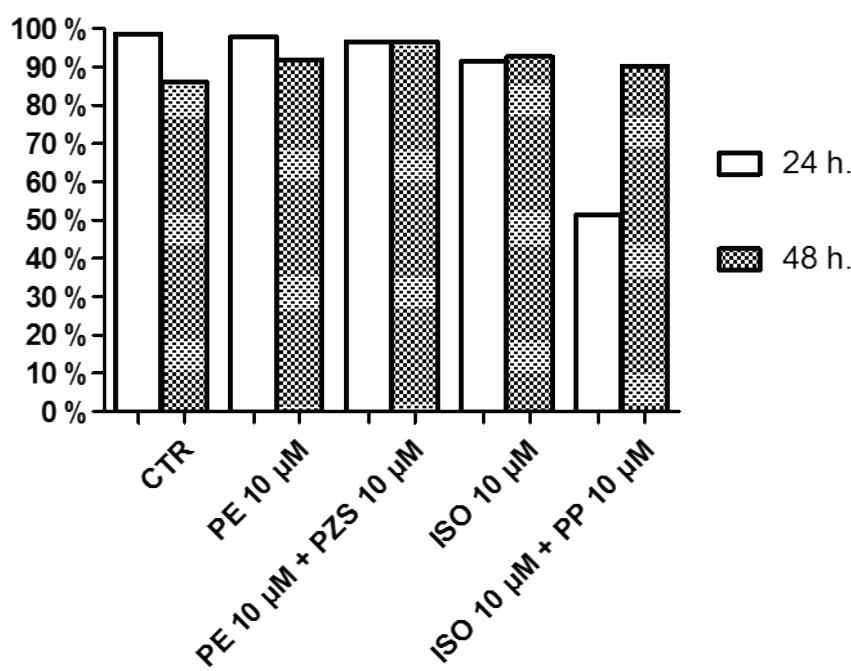

Fig. 2. Characteristics of FCM: cell count and viability of different subgroups of HCF cell culture after 24 and 48 hours of medium culture. CTR - control sample; PE - phenylephrine; PZS - prazosin; ISO - isoprenaline; PP - propranolol.

\section{Results}

\section{HCF culture activation}

The number of cells and viability in all groups were characterized by flow cytometry (Fig. 1, Fig. 2). After pharmacological stimulation, no statistically significant differences were observed. Average cell viability was $>85 \%$ in all cases, except one subgroup. By evaluating the positivity of $\mathrm{HCF}$ for $\mathrm{CD}$ markers typical for cells of mesenchymal origin (CD73, CD105) and those that are not (CD14, CD20, CD34 and CD45), we did not observe a statistically significant difference between the individual groups. The percentage of cells positive for mesenchymal markers ranged from $85 \%$, in all time intervals, as well as in all incubation conditions. Vice versa, the expression of expected 'negative' markers was $<15 \%$ in our HCF culture. However, for the CD90 marker, which was previously considered the gold standard for fibroblast identification, it was only at the level of $5 \%$. Furtado et al. (2014) in their study on mouse cardiac fibroblasts confirmed that the degree of positivity of fibroblasts for CD90 is not clearly defined and can vary considerably between subgroups of fibroblasts, and suggested that CD90 cannot be considered a specific marker.

The relative expression of the collagen 3 gene was significantly increased in the groups of cells affected by different exposure times and concentrations of isoprenaline (Fig. 3). As expected, the relative expression of collagen 1 and 3 genes in selected propranolol-added 
groups was significantly reduced. In addition, these observed changes were confirmed by measuring the concentration of soluble collagen in the cell medium (Fig. 4). The action of phenylephrine induced a significant increase in the relative concentration of collagen in the cell medium in selected groups. This change did not occur with the addition of a specific antagonist (prazosin or propranolol) and in selected groups, the concentration of soluble collagen in the cell medium was even significantly reduced after the addition of these substances. The absence of significant changes in the selected subgroups could be due to the relatively large number of different subgroups and the resulting small number of samples from that exact subgroup.
Col1A1
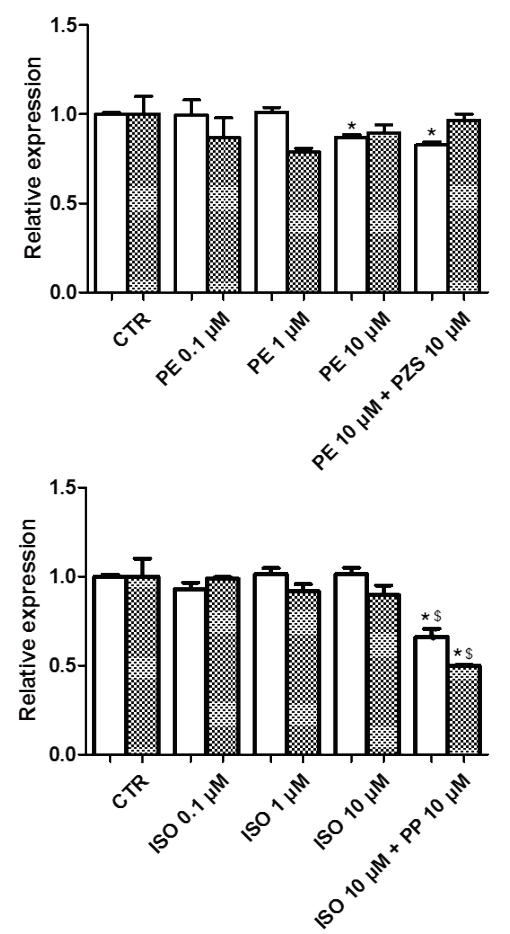

Col3A1
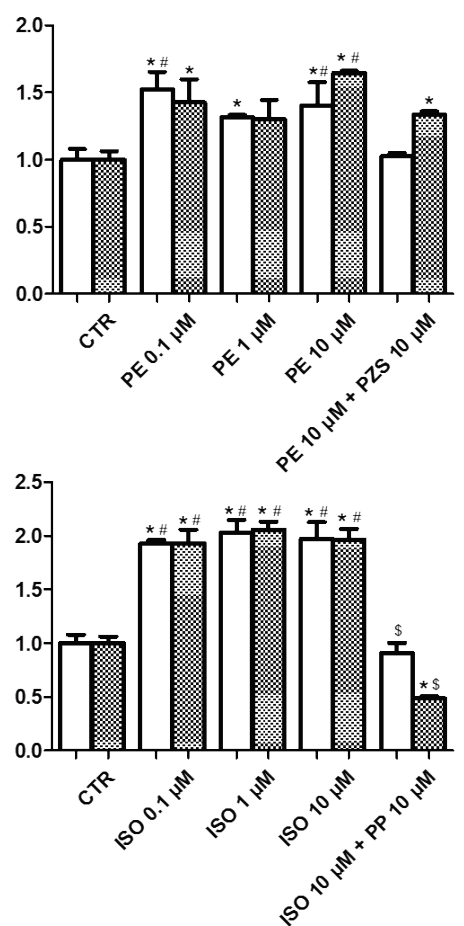

Col1A1/Col3A1 ratio
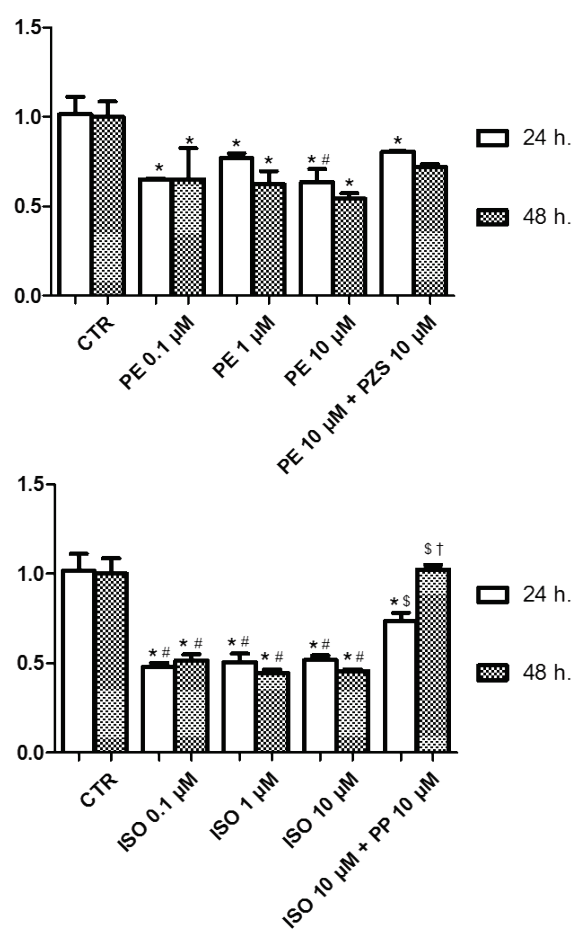

Fig. 3. Relative expression of Col1A1 (left) and Col3A1 genes (middle) in HCF cell culture after 24 and 48 culture in medium with different concentrations of phenylephrine (PE) and prazosin (PZS) (top) or isoprenaline (ISO) and propranolol (PP) (bottom). The relative expression ratio of the Col1A1 / Col3A1 genes showed on the right, ${ }^{*} p<0.05$ vs. CTR, $\# p<0.05$ vs. antagonist group, $\$ p<0.05$ vs. all groups with different concentrations without antagonist, $+p<0.05$ vs. 24 hours group.

\section{Relative soluble collagen concentration}
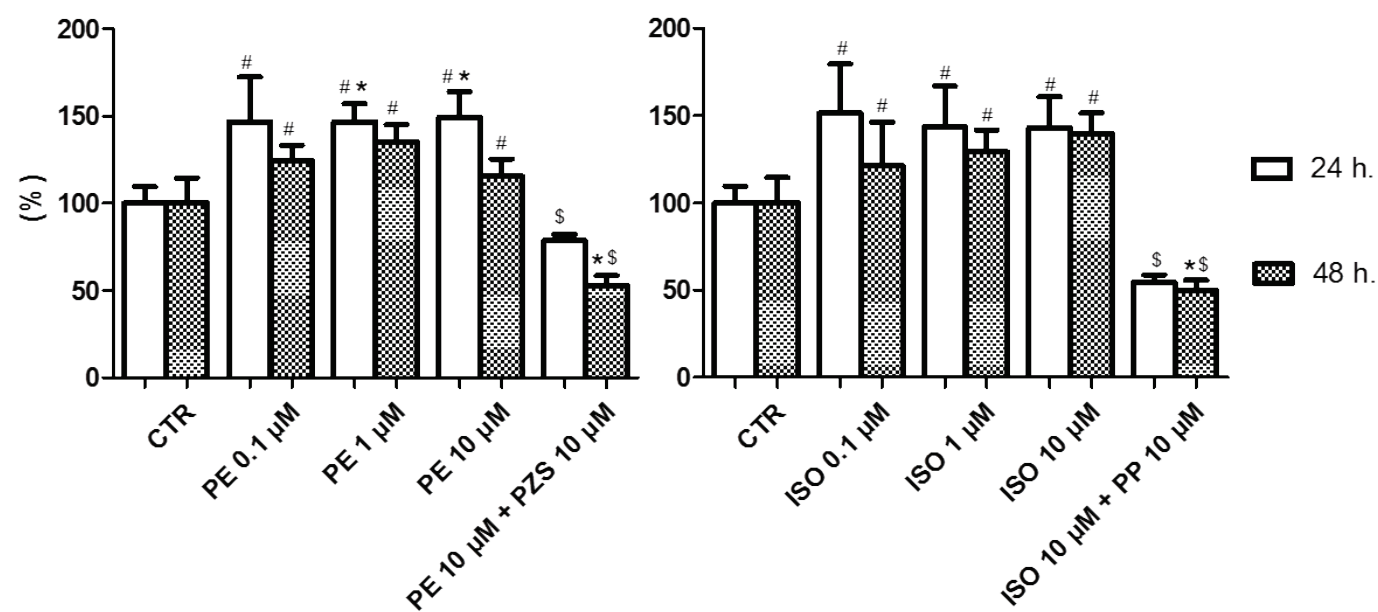

Fig. 4. Relative concentration of soluble collagen in HCF cell medium after 24 and 48 cultivation in medium with different concentrations of isoprenaline (ISO), propranolol (PP), and phenylephrine (PE) and prazosin (PZS), *p<0.05 vs. CTR, \#p<0.05 vs. antagonist group, $\$ \mathrm{p}<0.05$ vs. all groups with different concentrations without antagonist. 
A significant decrease in the relative expression ratio of collagen 1 and 3 was also observed in all pharmacologically affected groups by an average of $45 \%$ (isoprenaline group decreased by more than $50 \%$ decrease). Overall, however, we can assume a successful induction of fibroblast activation based on the observed changes.

\section{Expression of Orai channel isoforms}

Phenylephrine did not alter the relative expression of the Orai gene isoforms in HCF, but an approximately $25 \%$ decrease in Orai 1 isoform expression was observed with the addition of prazosin (Fig. 5). The most significant changes we observed were in cells treated with isoprenaline. The relative expression of the Orai2 gene was significantly increased in all selected time periods and concentrations from 27 to $43 \%$ (average of $35 \%$ ). This increase was significantly inhibited by the addition of propranolol, when there was an even average decrease in relative expression of approximately $20 \%$. Changes in Orai3 isoform expression were also observed,expression in this group was more than $200 \%$. These changes were also reflected in the change in the expression profile of the Orail / Orai3 ratio. With increasing isoprenaline concentration, this ratio decreased from 7 to $12 \%$, and with the addition of propranolol it even decreased by an average of $44 \%$.
Orai1

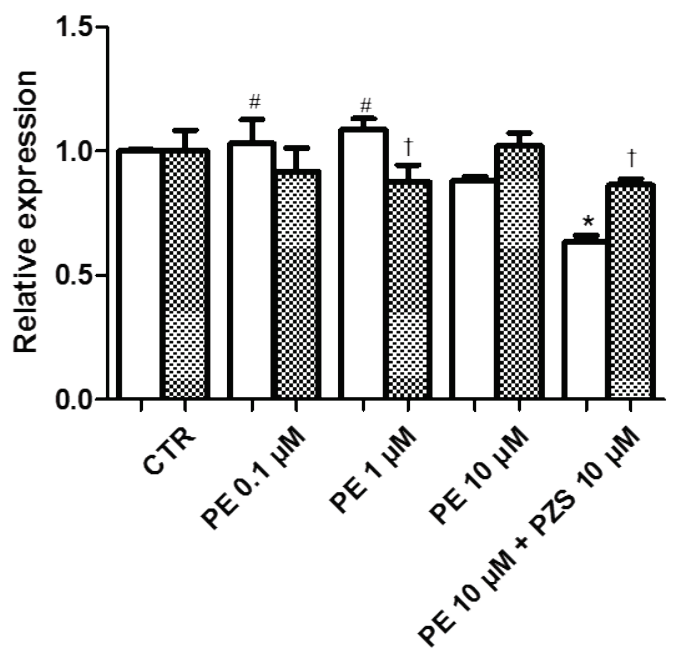

Orai3

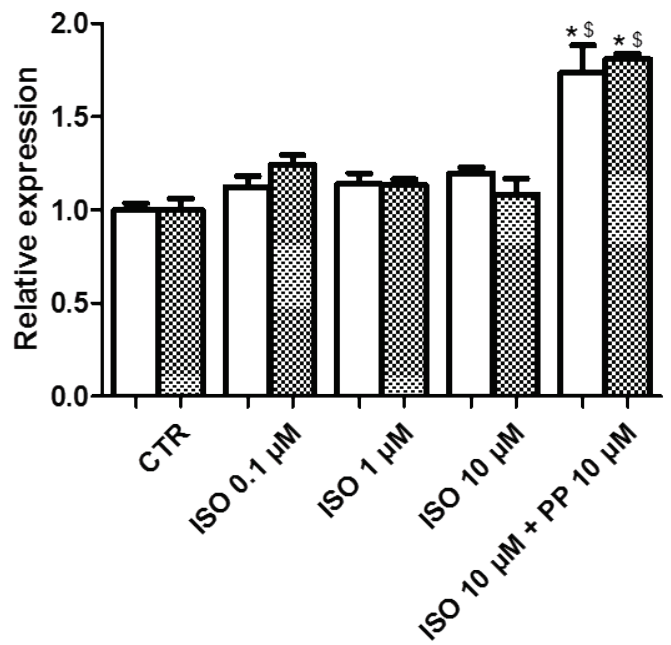

Orai2

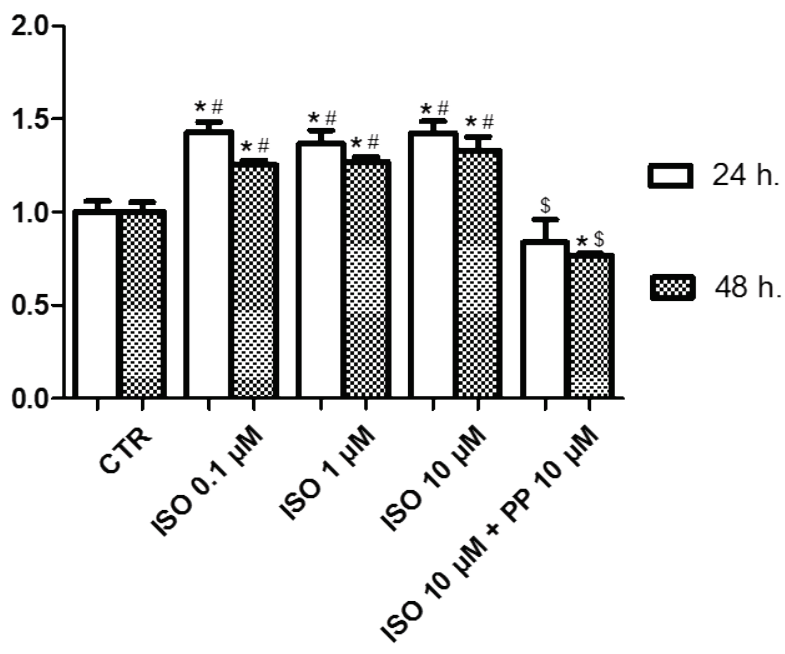

Orai1/Orai3 ratio

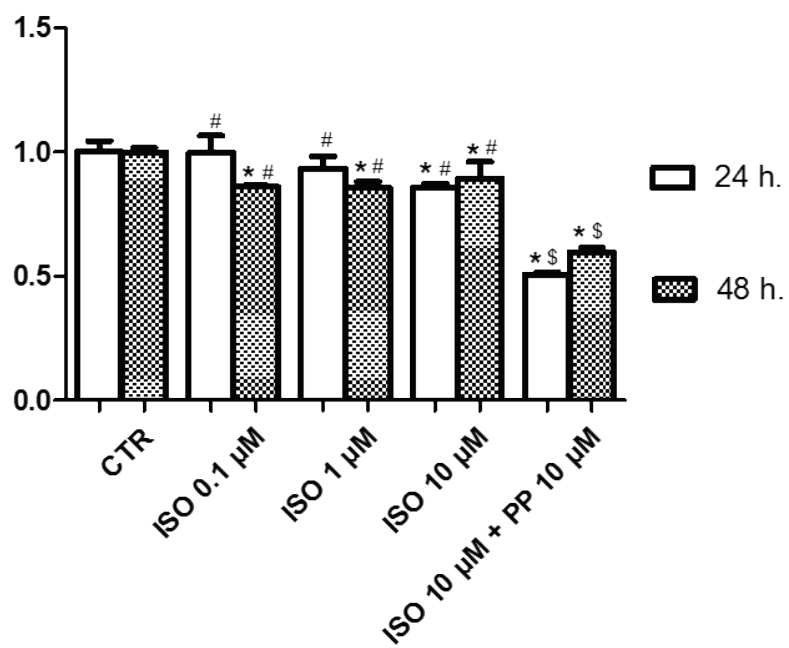

Fig. 5. Relative gene expression of individual Orai isoforms: Orai1 (top left), Orai2 (top right) and Orai3 (bottom left) and the ratio of Orai1 to Orai3 expression (bottom right) in HCF cell culture after 24 and 48 cultivation in medium with different concentrations of isoprenaline (ISO) and propranolol (PP) $* \mathrm{p}<0.05$ vs. CTR, $\# \mathrm{p}<0.05$ vs. antagonist group, $\$ \mathrm{p}<0.05$ vs. all groups with different concentrations without antagonist, $+p<0.05$ vs. 24 hours group. 
STIM1

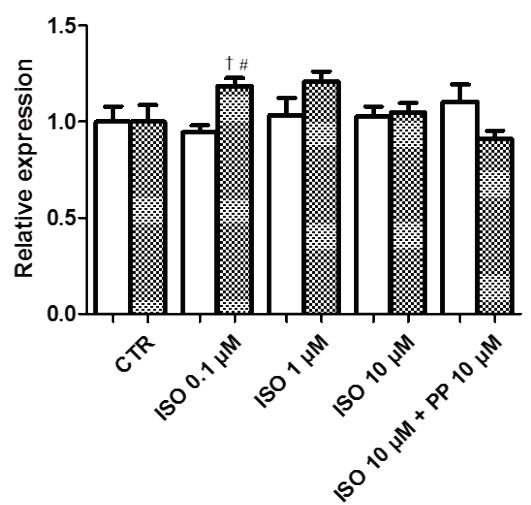

STIM2

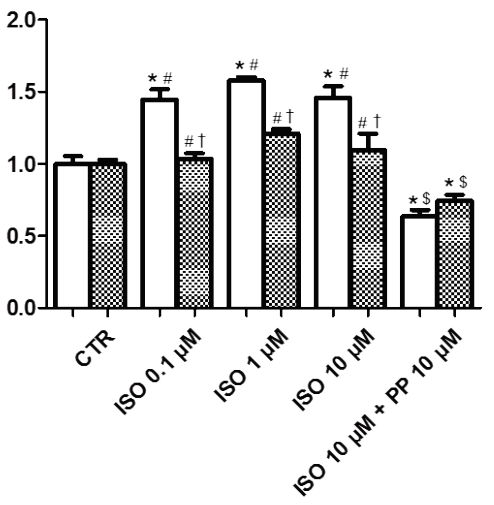

STIM2.1/STIM2 ratio

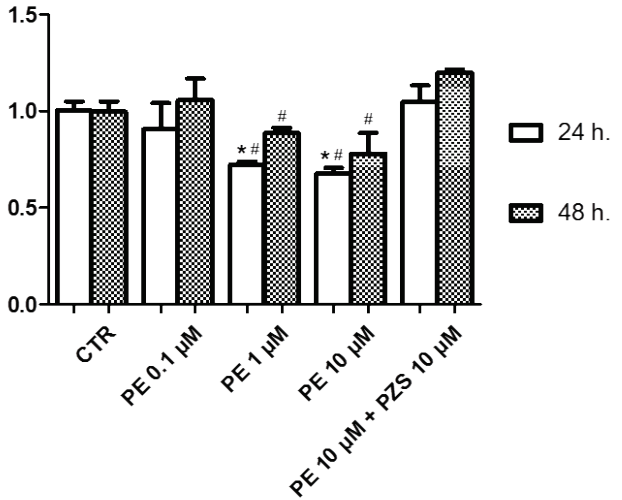

Fig. 6. Relative gene expression of the STIM2 isoform (left) in HCF cell culture after 24 and 48 cultivation in medium with different concentrations of isoprenaline (ISO) and propranolol (PP) and the ratio of STIM2.1 to STIM2 expression (right) affected by phenylephrine (PE) and prazosin (PZS), $* p<0.05$ vs. CTR, $\# p<0.05$ vs. antagonist group, $\$ p<0.05$ vs. all groups with different concentrations without antagonist, $+p<0.05$ vs. group 24 hours.

\section{Expression of STIM splicing variants}

Although we did not observe significant changes in the relative expression of the STIM1 isoform except one group, the situation was more interesting for both the STIM2 isoform and the STIM2.1/STIM2 ratio (Fig. 6). As with the Orai2 isoform, isoprenaline significantly increased the relative expression of STIM2 in selected groups, by an average of $30 \%$, and these changes were observed especially after 24 hours. In contrast, the relative expression of this gene decreased significantly with the addition of propranolol by $25-36 \%$. A similar trend was observed in the change in the STIM2.1/2 ratio due to the action of alpha receptors. Phenylephrine, with increasing concentration, reduced this ratio by more than $30 \%$ in selected groups, and this change was inhibited by the addition of prazosin and in one group, a significant $20 \%$ increase was observed.

\section{Discussion}

Most of the focus in cardiovascular research is on cardiomyocyte function, with little attention to fibroblasts and ECM production, which play an equally important role in the pathogenesis of many cardiovascular diseases (Ross et al. 2017). Recently, we described changes in specific mechanisms of SOCE in the heart during heart failure (Čendula et al. 2019). Therefore, the possibility of the involvement of calcium signaling in the fibroblast compartment was intriguing. The success of induction of cell-cultured fibroblasts into the activated state was evaluated by determining the soluble collagen in the cell medium and the amount of mRNA for specific genes by the qRT-PCR method. Interestingly, $\alpha$-SMA is considered one of the most important markers of fibroblast activation, but no significant changes in relative expression of this gene were observed in our experiment. The expression of $\alpha$-SMA can be significantly increased in the early stages of pathological conditions such as myocardial infarction, but after a longer period of time it is reduced, as also confirmed by a study using cardiac fibroblasts and myofibroblasts (Fu et al. 2018). However, we observed an increase in the concentration of soluble collagen, as well as a change in the relative expression of the collagen 3 gene, which indicated successful transdifferentiation to myofibroblasts. Similarly, like Ross et al. 2017, we did not observe an increase in relative expression of the Col1 A1 gene during activation of selected receptors, but we observed a decrease with the effect of an antagonist, confirming a specific effect of agonists and suggesting a positive effect of pharmacological treatment in cardiovascular diseases. The altered ratio of relative expression of Col1/Col3 indicates, according to several studies (Uchinaka et al. 2016, Pauschinger et al. 1998, Wei et al. 1999), a possible adaptation mechanism in the myocardium under various pathological conditions.

\section{Expression of Orai channels and STIM splicing variants}

The most significant changes in SOCE component regulation were observed when affecting beta receptors. An increase in the Orai2 isoform was observed, as well as a decrease in the ratio of Orail to Orai3. However, the observed changes suggest the involvement of other Orai isoforms in the whole SOCE mechanism, as these are often overlooked. Although most studies focused on the role of Orai1, an increasing number of 
new studies emphasizes the importance of Orai2 isoforms also in the cardiovascular system (Gammons et al. 2021). Orai2 has been suggested to form heteromeric calcium channels with TRPC6 and increase SOCE signaling under pathological conditions in pulmonary smooth muscle cells and hippocampal neurons (Zhang et al. 2016, Fernandez et al. 2015). The observed increased expression of Orai2 in activated fibroblasts could lead to enhanced formation of such channels, presenting a mechanism in which increased SOCE contributes to fibroblast activation after adrenergic stimulation. Even more important findings emerge from changes in STIM isoforms. No changes were observed in the expression profile of the STIM1 isoform, as we expected (Mohis et al. 2018). However, the STIM2 isoform and its relationship with the infant STIM2.1 isoform were significantly changed. The decreased relative abundance of SOCE-inhibiting STIM2.1 (demonstrated by the decreased STIM2.1/STIM2 ratio) possibly leads to increased SOCE in activated fibroblasts. Although several cellular pathways are involved in calcium regulation in fibroblasts, these changes indicate the crucial involvement of Orai and STIM proteins in the entry of calcium operated in the store. Subsequent increase in intracellular $\mathrm{Ca}^{2+}$ concentration activates calcineurin / NFAT and other pathways to promote profibrotic gene expression leading to the development of cardiac fibrosis (Feng et al. 2019).

\section{Study limitations}

The main limitation of this study is the reliance on the use of qRT-PCR to quantify expressional changes and the related assumption of a direct dependence of functional proteins and their post-translational modifications on the level of mRNA. Verification of these described expressional changes at the protein level is crucial and complicated by the lack of suitable antibodies. Furthermore, inhibition of specific SOCE regulatory and functional proteins needs to be used for detailed characterization of processes involved in fibroblast activation.

\section{Conclusions}

By activation of alpha and beta receptors on fibroblasts, we achieved their activation observed as changes in relative expression and ratios of collagen gene isoforms as well as its content in the cell culture medium. An increase in Orai2 isoform expression, a change in the ratio of Orai1 and Orai3, as well as an increase in activation and a decrease in inhibitory STIM2 isoforms were observed. The suggested association of fibroblast activation with the SOCE mechanism is possible, but more studies are required to confirm this hypothesis. However, these results supplement the mosaic of changes in SOCE regulation in several pathological processes and different types of heart cells, providing a stable platform for further research.

\section{Conflict of Interest}

There is no conflict of interest.

\section{Acknowledgements}

This study was supported by the Faculty of Pharmacy of Comenius University, Bratislava, Slovak Republic (FaF UK/3/2020, FaF UK/7/2021).

\section{References}

BOOTMAN MD, RIETDORF K: Tissue specificity: store-operated $\mathrm{Ca}^{2+}$ entry in cardiac myocytes. Adv Exp Med Biol 993: 363-387, 2017. https://doi.org/10.1007/978-3-319-57732-6_19

CECCATO TL, STARBUCK RB, HALL JK, WALKER CJ, BROWN TE, KILLGORE JP, ANSETH KS, LEINWAND LA: Defining the cardiac fibroblast secretome in a fibrotic microenvironment. J Am Heart Assoc 9: 19, 2020. https://doi.org/10.1161/JAHA.120.017025

CHEN W, BIAN W, ZHOU Y, ZHANG J: Cardiac fibroblasts and myocardial regeneration. Front Bioeng Biotechnol 9: 599928, 2021. https://doi.org/10.3389/fbioe.2021.599928

COVINGTON ED, WU MM, LEWIS RS: Essential role for the CRAC activation domain in store-dependent oligomerization of STIM1. Mol Biol Cell 21: 1897-1907, 2010. https://doi.org/10.1091/mbc.e10-02-0145

ČENDULA R, DRAGÚN M, GAŽOVÁ A, KYSELOVIČ J, HULMAN M, MÁŤUŠ M: Changes in STIM isoforms expression and gender-specific alterations in Orai expression in human heart failure. Physiol Res 68 (Suppl 2): S165-S172, 2019. https://doi.org/10.33549/physiolres.934300 
FENG J, ARMILLEI MK, YU AS, LIANG BT, RUNNELS LW, YUE L: $\mathrm{Ca}^{2+}$ Signaling in cardiac fibroblasts and fibrosis-associated heart diseases. J Cardiovasc Dev Dis 6: 34, 2019. https://doi.org/10.3390/jcdd6040034

FERNANDEZ RA, WAN J, SONG S, SMITH KA, GU Y, TAUSEEF M, TANG H, MAKINO A, MEHTA D, YUAN JX: Upregulated expression of STIM2, TRPC6, and Orai2 contributes to the transition of pulmonary arterial smooth muscle cells from a contractile to proliferative phenotype. Am J Physiol Cell Physiol 308: C581-C593, 2015. https://doi.org/10.1152/ajpcell.00202.2014

FU X, KHALIL H, KANISICAK O, BOYER JG, VAGNOZZI RJ, MALIKEN BD, SARGENT MA, PRASAD V, VALIENTE-ALANDI I, BLAXALL BC, MOLKENTIN JD: Specialized fibroblast differentiated states underlie scar formation in the infarcted mouse heart. J Clin Invest 128: 2127-2143, 2018. https://doi.org/10.1172/JCI98215

FURTADO MB, COSTA MW, PRANOTO EA, SALIMOVA E, PINTO AR, LAM NT, PARK A, SNIDER P, CHANDRAN A, HARVEY RP, BOYD R, CONWAY SJ, PEARSON J, KAYE DM, ROSENTHAL NA. Cardiogenic genes expressed in cardiac fibroblasts contribute to heart development and repair. Circ Res 114 : 1422-1434, 2014. https://doi.org/10.1161/CIRCRESAHA.114.302530

GAMMONS J, TREBAK M, MANCARELLA S: Cardiac-specific deletion of Orai3 leads to severe dilated cardiomyopathy and heart failure in mice. J Am Heart Assoc 10:e019486, 2021. https://doi.org/10.1161/JAHA.120.019486

LEWIS RS: Store-operated calcium channels: new perspectives on mechanism and function. Cold Spring Harb Perspect Biol 3: a003970, 2011. https://doi.org/10.1101/cshperspect.a003970

MOHIS M, EDWARDS S, RYAN S, RIZVI F, TAJIK AJ, JAHANGIR A, ROSS GR: Aging-related increase in storeoperated $\mathrm{Ca}^{2+}$ influx in human ventricular fibroblasts. Am J Physiol Heart Circ Physiol 315: H83-H91, 2018. https://doi.org/10.1152/ajpheart.00588.2017.

MUIK M, FAHRNER M, SCHINDL R, STATHOPULOS P, FRISCHAUF I, DERLER I, PLENK P, LACKNER B, GROSCHNER K, IKURA M, ROMANIN C: STIM1 couples to ORAI1 via an intramolecular transition into an extended conformation. EMBO J, 30: 1678-1689, 2011. https://doi.org/10.1038/emboj.2011.79

PAUSCHINGER M, DOERNER A, REMPPIS A, TANNHÄUSER R, KÜHL U, SCHULTHEISS HP: Differential myocardial abundance of collagen type I and type III mRNA in dilated cardiomyopathy: effects of myocardial inflammation. Cardiovasc Res 37: 123-129, 1998. https://doi.org/10.1016/S0008-6363(97)00217-4

PUTNEY JW: Origins of the concept of store-operated calcium entry. Front Biosci Scholar Ed 3: 980-984, 2011. https://doi.org/10.2741/s202

PUTNEY JW, STEINCKWICH-BESANÇON N, NUMAGA-TOMITA T, DAVIS FM, DESAI PN, D'AGOSTIN DM, BIRD GS: The functions of store-operated calcium channels. Biochim Biophys Acta Mol Cell Res 1864: 900-906, 2017. https://doi.org/10.1016/j.bbamcr.2016.11.028

RANA A, YEN M, SADAGHIANI AM, MALMERSJÖ S, PARK CY, DOLMETSCH RE, LEWIS RS: Alternative splicing converts STIM2 from an activator to an inhibitor of store-operated calcium channels. J Cell Biol 209: 653-669, 2015. https://doi.org/10.1083/jcb.201412060

RANJAN P, KUMARI R, VERMA SK: Cardiac fibroblasts and cardiac fibrosis: precise role of exosomes. Front Cell Dev Biol 7: 318, 2019. https://doi.org/10.3389/fcell.2019.00318

ROSENBERG P, KATZ D, BRYSON V: SOCE and STIM1 signaling in the heart: Timing and location matter. Cell Calcium 77: 20-28, 2019. https://doi.org/10.1016/i.ceca.2018.11.008

ROSENBERG P, ZHANG H, BRYSON VG, WANG C: SOCE in the cardiomyocyte: the secret is in the chambers. Pflugers Arch - Eur J Physiol 473: 417-434, 2021. https://doi.org/10.1007/s00424-021-02540-3

ROSADO JA, DIEZ R, SMANI T, JARDÍN I: STIM and Orai1 Variants in Store-Operated Calcium Entry. Front Pharmacol 6: 325, 2016. https://doi.org/10.3389/fphar.2015.00325

ROSS GR, BAJWA TJR, EDWARDS S, EMELYANOVA L, RIZVI F, HOLMUHAMEDOV EL, WERNER P, DOWNEY FX, TAJIK AJ, JAHANGIR A: Enhanced store-operated $\mathrm{Ca}^{2+}$ influx and ORAI1 expression in ventricular fibroblasts from human failing heart. Biol Open 6: 326-332, 2017. https://doi.org/10.1242/bio.022632

RUHLE B, TREBAK M: Emerging roles for native ORAI $\mathrm{Ca}^{2+}$ channels in cardiovascular disease. Curr Top Membr 71, 209-235, 2013. https://doi.org/10.1016/B978-0-12-407870-3.00009-3 
SAUL S, STANISZ H, BACKES CS, SCHWARZ EC, HOTH M: How ORAI and TRP channels interfere with each other: Interaction models and examples from the immune system and the skin. Eur J Pharmacol 739, 49-59, 2014. https://doi.org/10.1016/j.ejphar.2013.10.071

SERAFINI M, CORDERO-SANCHEZ C, DI PAOLA R, BHELA IP, APRILE S, PURGHÈ B, FUSCO R, CUZZOCREA S, GENAZZANI AA, RIVA B, PIRALI T: Store-operated calcium entry as a therapeutic target in acute pancreatitis: discovery and development of drug-like SOCE inhibitors. J Med Chem 63: 14761-14779, 2020. https://doi.org/10.1021/acs.jmedchem.0c01305

ZHANG H, SUN S, WU L, PCHITSKAYA E, ZAKHAROVA O, FON TACER K, BEZPROZVANNY I: Storeoperated calcium channel complex in postsynaptic spines: a new therapeutic target for Alzheimer's disease treatment. J Neurosci 36: 11837-11850, 2016. https://doi.org/10.1523/JNEUROSCI.1188-16.2016

TALLQUIST M, MOLKENTIN J: Redefining the identity of cardiac fibroblasts. Nat Rev Cardiol 14: 484-491, 2017. https://doi.org/10.1038/nrcardio.2017.57

UCHINAKA A, YOSHIDA M, TANAKA K, HAMADA Y, MORI S, MAENO Y, MIYAGAWA S, SAWA Y, NAGATA K, YAMAMOTO H, KAWAGUCHI N: Overexpression of collagen type III in injured myocardium prevents cardiac systolic dysfunction by changing the balance of collagen distribution. J Thorac Cardiovasc Surg 156: 217-226.E3, 2018. https://doi.org/10.1016/j.jtcvs.2018.01.097

WEI S, CHOW LT, SHUM IO, QIN L, SANDERSON JE: Left and right ventricular collagen type I/III ratios and remodeling post-myocardial infarction. J Card Fail 5: 117-126, 1999. https://doi.org/10.1016/S10719164(99)90034-9

WEN J, HUANG YC, XIU HH, SHAN ZM, XU KQ: Altered expression of stromal interaction molecule (STIM)calcium release-activated calcium channel protein (ORAI) and inositol 1,4,5-trisphosphate receptors (IP3Rs) in cancer: will they become a new battlefield for oncotherapy? Chin J Cancer 35: 32, 2016. https://doi.org/10.1186/s40880-016-0094-2 